\title{
Expression and clinical value of EGFR in human meningiomas
}

\author{
Magnus B Arnli Corresp.. ${ }^{1}$, Thomas Backer-Grøndahl ${ }^{1}$, Borgny Ytterhus ${ }^{1}$, Unn S Granli ${ }^{1,2}$, Stian Lydersen ${ }^{3}$, \\ Sasha Gulati ${ }^{4}$, Sverre Helge Torp ${ }^{1,5}$ \\ 1 Department of Laboratory Medicine, Children's and Women's Health, Faculty of Medicine and Health Sciences, Norwegian University of Science and \\ Technology (NTNU), Trondheim, Norway \\ ${ }^{2}$ Cellular and Molecular Imaging Core Facility (CMIC), Norwegian University of Science and Technology (NTNU), Trondheim, Norway \\ 3 Regional Centre for Child and Youth Mental Health and Child Welfare, Department of Mental Health, Faculty of Medicine and Health Sciences, Norwegian \\ University of Science and Technology (NTNU), Trondheim, Norway \\ 4 Department of Neurosurgery, St. Olavs Hospital, Trondheim, Norway \\ 5 Department of Pathology, St. Olavs Hospital, Trondheim, Norway \\ Corresponding Author: Magnus B Arnli \\ Email address: magnuarn@stud.ntnu.no
}

Background: Meningiomas are common intracranial tumors in humans that frequently recur despite having a predominantly benign nature. Even though these tumors have been shown to commonly express EGFR/c-erbB1 (epidermal growth factor receptor), results from previous studies are uncertain regarding the expression of either intracellular or extracellular domains, cellular localization, activation state, relations to malignancy grade, and prognosis. Aims: This study was designed to investigate the expression of the intracellular and extracellular domains of EGFR and of the activated receptor as well as its ligands EGF and TGF $\alpha$ in a large series of meningiomas with long follow-up data, and investigate if there exists an association between antibody expression and clinical and histological data. Methods: A series of 186 meningiomas consecutively operated within a 10-year period was included. Tissue microarrays were constructed and immunohistochemically analyzed with antibodies targeting intracellular and extracellular domains of EGFR, phosphorylated receptor, and EGF and TGF $\alpha$. Expression levels were recorded as a staining index (SI). Results: Positive immunoreactivity was observed for all antibodies in most cases. There was in general high SIs for the intracellular domain of EGFR, phosphorylated EGFR, EGF, and TGF $\alpha$ but lower for the extracellular domain. Normal meninges were negative for all antibodies. Higher SIs for the phosphorylated EGFR were observed in grade II tumors compared with grade I $(p=0.018)$. Survival or recurrence was significantly decreased in the time to recurrence analysis (TTR) with high SI-scores of the extracellular domain in a univariable survival analysis (HR 1.152, $\mathrm{Cl}$ (1.036 to 1.280, $p=0.009)$ ). This was not significant in a multivariable analysis. Expression of the other antigens did not affect survival. Conclusion: EGFR is overexpressed and in an activated state in human meningiomas. High levels of ligands also support this growth factor 
receptor system to be involved in meningioma tumorigenesis. EGFR may be a potential candidate for targeted therapy. 


\section{Expression and clinical value of EGFR in}

\section{2 human meningiomas}

4 Magnus B Arnli ${ }^{1}$, Thomas Backer-Grøndahl ${ }^{1}$, Borgny Ytterhus ${ }^{1}$, Unn S Granli ${ }^{1,2}$, Stian

5 Lydersen ${ }^{3}$, Sasha Gulati ${ }^{4}$, Sverre H Torp ${ }^{1,5}$

6

7 'Department of Laboratory Medicine, Children's and Women's Health, Faculty of Medicine and

8 Health Sciences, Norwegian University of Science and Technology (NTNU), Trondheim,

9 Norway.

$10{ }^{2}$ Cellular and Molecular Imaging Core Facility (CMIC), Norwegian University of Science and

11 Technology (NTNU), Trondheim, Norway.

$12{ }^{3}$ Regional Centre for Child and Youth Mental Health and Child Welfare, Department of Mental

13 Health, Faculty of Medicine and Health Sciences, Norwegian University of Science and

14 Technology (NTNU), Trondheim, Norway.

$15{ }^{4}$ Department of Neurosurgery, St. Olavs Hospital, Trondheim, Norway.

$16{ }^{5}$ Department of Pathology, St. Olavs Hospital, Trondheim, Norway.

18 Corresponding Author:

19 Magnus B Arnli ${ }^{1}$

20

21 Email address: magnuarn@stud.ntnu.no 


\section{Abstract}

23 Background: Meningiomas are common intracranial tumors in humans that frequently recur

24 despite having a predominantly benign nature. Even though these tumors have been shown to

25 commonly express EGFR/c-erbB1 (epidermal growth factor receptor), results from previous

26 studies are uncertain regarding the expression of either intracellular or extracellular domains,

27 cellular localization, activation state, relations to malignancy grade, and prognosis.

28 Aims: This study was designed to investigate the expression of the intracellular and extracellular

29 domains of EGFR and of the activated receptor as well as its ligands EGF and TGF $\alpha$ in a large

30 series of meningiomas with long follow-up data, and investigate if there exists an association

31 between antibody expression and clinical and histological data.

32 Methods: A series of 186 meningiomas consecutively operated within a 10-year period was

33 included. Tissue microarrays were constructed and immunohistochemically analyzed with

34 antibodies targeting intracellular and extracellular domains of EGFR, phosphorylated receptor,

35 and EGF and TGFa. Expression levels were recorded as a staining index (SI).

36 Results: Positive immunoreactivity was observed for all antibodies in most cases. There was in

37 general high SIs for the intracellular domain of EGFR, phosphorylated EGFR, EGF, and TGF $\alpha$

38 but lower for the extracellular domain. Normal meninges were negative for all antibodies. Higher

39 SIs for the phosphorylated EGFR were observed in grade II tumors compared with grade I

$40(p=0.018)$. Survival or recurrence was significantly decreased in the time to recurrence analysis

41 (TTR) with high SI-scores of the extracellular domain in a univariable survival analysis (HR

421.152 , CI (1.036 to $1.280, \mathrm{p}=0.009))$. This was not significant in a multivariable analysis.

43 Expression of the other antigens did not affect survival.

44 Conclusion: EGFR is overexpressed and in an activated state in human meningiomas. High 
45 levels of ligands also support this growth factor receptor system to be involved in meningioma 46 tumorigenesis. EGFR may be a potential candidate for targeted therapy.

47 
Introduction

50

51 Meningiomas account for approximately $30 \%$ of intracranial tumors in adults, and despite being

52 predominantly benign, many cases recur (Backer-Grondahl et al. 2012; Louis et al. IARC: Lyon

53 2007; Willis et al. 2005). Biomarkers capable of identifying recurrent cases could provide better

54 treatment options and closer follow-up for such patients. A potential candidate is the epidermal

55 growth factor receptor (EGFR), which has been shown to be overexpressed and/or amplified in

many human cancers (Libermann et al. 1984; Rokita et al. 2013; Salomon et al. 1995; Torp et al.

1991). Ligands such as EGF (epidermal growth factor) and TGF $\alpha$ (transforming growth factor

alpha) bind to the extracellular domain (ECD) of the receptor, leading to effects on

differentiation, growth, migration, adhesion, or apoptosis (Yarden \& Sliwkowski 2001).

60

EGFR and the ligands EGF and TGF $\alpha$ have been shown to be overexpressed in human

meningiomas (Andersson et al. 2004; Baxter et al. 2014; Caltabiano et al. 2013; Camby et al.

1997; Carroll et al. 1997; Diedrich et al. 1995; Guillaudeau et al. 2012; Halper et al. 1999;

Johnson et al. 1994; Kuratsu et al. 1994; Laurendeau et al. 2009; Lusis et al. 2005; Maiuri et al.

2007; Narla et al. 2014; Reubi et al. 1989; Torp et al. 1992; Wernicke et al. 2010), whereas non-

neoplastic meningeal tissue show sparse or no reactivity (Carroll et al. 1997; Johnson et al. 1994;

67 Torp et al. 1992), indicating a potential tumorigenic role of EGFR in these tumors Both

membranous and cytoplasmic EGFR immunoreactivity have been described in meningiomas

69 (Guillaudeau et al. 2012; Halper et al. 1999; Horsfall et al. 1989; Johnson et al. 1994; Jones et al.

70 1990; Smith et al. 2007; Torp et al. 1992), however, the prognostic relevance is scarcely

71 described (Guillaudeau et al. 2012). The receptor also seems to be activated (phosphorylated) 
72 (Carroll et al. 1997; Hilton et al. 2016). Moreover, the literature is conflicting regarding

73 expression levels of EGFR across malignancy grades, as some report increasing expression with

74 higher grades (Caltabiano et al. 2013; Diedrich et al. 1995; Halper et al. 1999) and others the

75 opposite or no connection at all (Baxter et al. 2014; Guillaudeau et al. 2012; Jones et al. 1990;

76 Kuratsu et al. 1994; Narla et al. 2014; Wernicke et al. 2010). Furthermore, the prognostic value

77 of expression of either the intracellular or extracellular domain of the receptor is uncertain

78 (Guillaudeau et al. 2012).

80 The aim of this study was to investigate the expression of the intracellular and extracellular

81 domains of EGFR, as well as its activated status and ligands in a large population-based series of

82 human meningiomas with long follow-up data and association with histopathological features, 83 meningioma subtypes, malignancy grade, and risk of recurrence.

85 Methods

86

87 Patient selection

88 The patient selection process has recently been described (Backer-Grondahl et al. 2012). In brief,

89 a search in the electronic patient data files at the pathology department was performed to find all

90 patients consecutively operated for meningiomas between the dates of 01.01 .1991 and

91 31.12.2000 at St. Olavs Hospital - Trondheim University Hospital, Norway. This hospital has

92 the sole responsibility for treating meningioma patients living in Central-Norway. The total

93 population is about 700000 (2013) (www.ssb.no 2013). Patients under the age of 18 years or

94 with intraspinal or non-primary meningioma were excluded. In the current study, 10 tumors were 
95 not found in the archives, providing a total of 186 primary tumors. Clinical and survival data for

96 patients and histological features have been presented earlier (Backer-Grondahl et al. 2014;

97 Backer-Grondahl et al. 2012). Patients were followed until the time of death or for a maximum 98 of 18 years.

Histological examination

101 Tumor biopsies were formalin-fixed and embedded in paraffin. Hematoxylin/eosin stained

102 sections were revised microscopically in order to verify diagnoses and to select representative

103 areas for tissue microarray (TMA). Representative areas were defined as meningioma tissue

104 lacking necrosis and with minimal connective- and vascular tissue, hemorrhages, and

105 calcifications. In cases with heterogeneous tissue, areas with different histological patterns were

106 chosen. Microscopic examination was done by two of the authors (MBA and SHT) in

107 collaboration using a Nikon Eclipse 80i microscope.

108

109 Tissue microarray construction

110 Construction of TMAs was achieved with an Alphelys Tissue Arrayer Minicore ${ }^{\circledR}$ 3, AH

111 diagnostics, with corresponding software (TMA Designer2) installed on a dedicated computer.

112 The TMAs were constructed with three cylinders from each biopsy, which has been shown to

113 have the highest level of concordance with whole-tissue sections in other tumors (Fernebro et al.

114 2002; Hoos et al. 2001; Rubin et al. 2002). The cylinder diameters were $1000 \mu \mathrm{m}$, and spaces

115 between cylinder borders were $600 \mu \mathrm{m}$. Each TMA block included a maximum of 24

116 meningioma cases, yielding 72 cylinders, with three additional cylinders from a liver biopsy for

117 orientation. In total, nine TMA blocks were constructed. 23 tumors were deemed unfit for TMA 
118 inclusion due to an insufficient amount of tumor tissue for cylinder extraction. In these cases,

119 whole-tissue sections were cut. The total number of cases analyzed on TMAs was 163.

120

121 Immunohistochemistry

122 Sections were cut with a thickness of $4 \mu \mathrm{m}$ on a microtome (Leica RM 2255), transferred to glass

123 slides (Superfrost ${ }^{\circledR}$ Plus, Thermo Scientific), dried over night at $37^{\circ} \mathrm{C}$, and later stored in a

124 freezing-unit. Prior to immunohistochemical staining, sections were heated at $60^{\circ} \mathrm{C}$ for one hour.

125 After deparaffinization, slides were pre-treated for antigen retrieval with PT Link (Dako) using

$126 \mathrm{pH} 9$ solution, except for the EGF antibody where proteinase K was used (10 min). Endogenous

127 peroxidase activity was extinguished using diluted hydrogen peroxide for 10 minutes. The

128 antibodies used were reactive against the extracellular domain of EGFR (clone EGFR.113, 1:10

129 dilution, 60 minutes incubation, mouse monoclonal Ab IgG2a, Novocastra, supplied by Leica

130 Biosystems), the cytoplasmic domain of EGFR (clone EGFR.25, 1:100 dilution, 60 minutes

131 incubation, mouse monoclonal Ab IgG1, Novocastra, supplied by Leica Biosystems), activated

132 (phosphorylated) EGFR (anti-phospho-EGFR (Tyr1173) antibody, 1:45 dilution, overnight

133 incubation at $4^{\circ} \mathrm{C}$, rabbit monoclonal, EMD Millipore), EGF (clone 10825, 1:180 dilution,

134 overnight incubation at $4^{\circ} \mathrm{C}$, monoclonal mouse IgG1, R\&D Systems), and TGF $\alpha$ (anti-TGF $\alpha$, ab

1359585 , 1:200 dilution, 60 minutes incubation, rabbit polyclonal Ab, Abcam). All antibodies were

136 incubated for 30 minutes with the detection system Dako EnVision ${ }^{\mathrm{TM}}+\mathrm{HRP}$, a dextran polymer

137 conjugated with secondary antibodies and horseradish peroxidase. Diaminobenzidin was used as

138 chromogen ( 2 × 5 minutes incubation $)$ and hematoxylin as counterstain. Positive controls

139 (placenta, skin, kidney, endometrium or breast) were included in each staining run (Uhlen et al.

140 2010). In the negative controls the primary antibodies were omitted. Dura and leptomeninges 
141 adjacent to the meningiomas served as a reference to normal tissue. EMA (epithelial membrane

142 antigen) (clone E29, 1:500 dilution, 40 minutes incubation, monoclonal mouse IgG2a, Dako)

143 was used to confirm the presence of meningioma tissue. Sections were stained using a Dako

144 AutostainerPlus.

145

146 Immunohistochemical analysis

147 Immunoreactivity was recorded as a staining index (SI) representing the product of intensity and

148 fraction of positive tumor cells (Torp et al. 2007). Intensity was subjectively evaluated as 0 (no

149 reaction), 1 (weak reaction), 2 (moderate reaction), or 3 (strong reaction). The fraction of

150 positive tumor cells was recorded as 0 (no positivity), 1 ( $<10 \%$ positive cells), $2(10-50 \%$

151 positive cells), or 3 ( $>50 \%$ positive cells) by a subjective estimate. TMA sections were scanned

152 using an Ariol scanning system (Ariol ${ }^{\mathrm{TM}}$ SL-50 3.3) with Genetix analysis system, and analyses

153 were conducted by the investigators on electronic images. An SI-score was calculated for each

154 tumor and used in statistical analyses. TMA tissue cores with $<50 \%$ remaining tissue after

155 sectioning and staining were excluded from analyses. Whole-tissue sections were evaluated

156 using a conventional microscope (Nikon Eclipse 50i). All cases were analyzed individually by

157 two of the authors, and discrepancies in findings were discussed and a consensus was reached.

158 Each meningioma patient was given an ID unique to this study, and the investigators were

159 consequently unaware of any case-specific clinical data during analysis.

160

161 Statistical analysis

162

163 The Mann-Whitney U test was used to compare SI between sample groups, according to 
164 histological features and malignancy grades. Meningioma subtypes ( $n=175$, subtypes with 1-2

165 cases were excluded from analysis) and tumor localization ( $\mathrm{n}=185$, one intraventricular tumor

166 was excluded from analysis) were compared using the Kruskal-Wallis test. When the Kruskal-

167 Wallis test was significant, pairwise comparisons between groups were performed using Dunn's

168 test and the Hommel adjustment ((Kirschner 2005), page 5191) for multiple comparisons and to

169 preserve the familywise error rate. Cox regression was used in both univariable and multivariable

170 survival analyses based on continuous SI-values. Simpson resection grade (1 and 2 vs. 3 and 4 )

171 (Backer-Grondahl et al. 2014), WHO performance status (0 and 1 vs 2, 3, 4 and 5), tumor grade

172 (grade I vs. grade II and III tumors), and age (continuous values) were included as covariates in

173 the multivariable analyses. The proportional hazard assumption was checked by visual inspection

174 of $\log$ minus log survival plots. Two measures for survival were investigated: time to recurrence

175 (TTR) and overall survival (OS). TTR was defined as either recurrence or disease-related death

176 (Punt et al. 2007). For TTR, survival was calculated after a maximum of 15 years with follow-

177 up. OS was calculated with 18 years of follow-up. Cohen's quadratic weighted kappa (computed

178 in StatXact 11) was used to assess inter-rater agreement. Hommel adjusted p-values were

179 computed in R. Other analyses were conducted using SPSS version 24.0 (SPSS Inc., Chicago,

180 IL). Two-sided $\mathrm{p}<0.05$ were considered statistically significant.

181

182 Ethics

183 The study has been approved by the Regional Committees for Medical and Health Research

184 Ethics (REK) (project number 4.2006.947). Waiver of consent was given by REK.

185

186 Results 
188 Clinical characteristics are presented in Table S1. Among the 186 meningiomas, $130(69.9 \%)$

189 were benign, $55(29.6 \%)$ atypical, and one (0.5\%) malignant (Table S2). The median age at the

190 date of operation was 59 years (range: 25-86), and the female to male ratio was 2.9:1. Results of

191 immunohistochemical analyses and SI related to histological features are shown in Tables 1 and

192 2, respectively. Typical immunostainings are shown in Fig. 1. No cases were excluded from the

193 study due to tissue loss or during processing failures. The TMA tissue cores were well preserved

194 after processing, and all three cores were intact for most cases. EMA immunoreactivity was seen

195 in 177/180 meningiomas (98.3\%) as well as in normal leptomeninges, which were negative for

196 the other antibodies.

197

198 (insert Table 1)

199 (insert Table 2)

200

201 ICD immunoreactivity was found in all meningioma cases at high levels with a median SI of

202 9.00. Concerning cellular localization, the ICD showed both membranous and cytoplasmic

203 staining, yet with a clear membranous predominance. There was no association between

204 expression of ICD and subtypes $(\mathrm{p}=0.765)$, localization $(\mathrm{p}=0.862)$, and malignancy grade

205 ( $p=0.983$, Table 2). However, ICD levels were high in tumors lacking psammoma bodies

$206(\mathrm{p}=0.005$, Table 2$)$.

207

208 Immunoreactivity for ECD was also observed in most cases (99.5\%), although the SI was much

209 lower than that observed for ICD with a median SI of 4.00. Membranous immunoreactivity was 
210 slightly stronger than cytoplasmic. The ECD was lower in fibrous tumors than in transitional

211 tumors $(p=0.028)$, atypical $(p=0.044)$, and meningothelial $(p=0.036)$. Further, the ECD was

212 higher in tumors presenting sheeting $(\mathrm{p}=0.035$, Table 2$)$, and in tumors lacking psammoma

213 bodies $(\mathrm{p}<0.001$, Table 2$)$. There was no association between either malignancy grade or

214 localization and ECD SI ( $\mathrm{p}=0.787$ and $\mathrm{p}=0.562$, respectively).

215

216 Phosphorylated EGFR was found in most cases $(99.5 \%)$ with a median SI of 9.00. Both

217 membranous and cytoplasmic immunostaining was present in most tumors, although the latter

218 demonstrated higher intensity. There was no association with any histological features.

219 Concerning malignancy, expression was higher in grade II tumors compared to grade I ( $\mathrm{p}=0.018$,

220 Table 2). Further, expression was lower in skull base than convexity $(\mathrm{p}<0.001)$ and falcine

221 tumors $(\mathrm{p}=0.038)$.

222

223

Immunoreactivity for EGF and TGF $\alpha$ was strong and seen in all cases with median SIs of 9.00.

224 Statistical analyses concerning histological features and malignancy grades were also performed

225 for grade I and grade II tumors individually (Tables S3 and S4, respectively.)

226

227 (insert Table 3)

228 (insert Table 4)

229

230 In univariable Cox regression analyses (Table 3), high ECD expression was significantly

231 associated with reduced survival or recurrence in the time to recurrence (TTR) analysis (HR

$2321.152, \mathrm{CI}$ (1.036 to 1.280$), \mathrm{p}=0.009)$. When tumor grades were analyzed individually for this 
233 antibody, a similar result was achieved only for benign tumors ( $\mathrm{n}=38, \mathrm{HR} 1.213$, CI (1.064 to

234 1.383), $\mathrm{p}=0.004$ ). In the multivariable survival analysis (Table 4), only Simpson resection grade

235 was significantly associated with worse TTR (HR 2.606, CI (1.558 to 4.359), $\mathrm{p}<0.001$ ), while

236 ECD expression did not show such association (HR 1.099, CI (0.987 to 1.222), $\mathrm{p}=0.084$ ). For

237 ICD, phosphorylated receptor, EGF, and TGF $\alpha$ no associations were found with TTR or OS

238 (Table 3), even when grades were analyzed separately.

239

240 (insert Table 3)

241 (insert Table 4)

242

243 Regarding $\kappa$-statistics variable scores were established (Table S5).

244

245 (insert Table 6)

246

247 Discussion

248

249 In the present study we have demonstrated that EGFR and its ligands EGF and TGF $\alpha$ are widely

250 expressed in human meningiomas and that the receptor appears to be in an activated state.

251 Increased ECD expression was associated with poorer survival in a univariable analysis.

252 However, it did not prove to be an independent predictor of survival in the multivariable 253 analysis.

255 Since normal meninges were EGFR immunonegative, our findings support a general 
256 upregulation of this receptor in meningioma tissue in accordance with previous results and other

257 studies (Carroll et al. 1997; Di Carlo et al. 1992; Halper et al. 1999; Horsfall et al. 1989;

258 Huisman et al. 1991; Johnson et al. 1994; Kuratsu et al. 1994; Laurendeau et al. 2009; Lusis et

259 al. 2005; Maiuri et al. 2007; Narla et al. 2014; Reubi et al. 1989; Torp et al. 1992). These

260 findings are also supported by studies in which EGFR expression in meningiomas was

261 determined by other techniques such as Northern and western blots, polymerase chain reactions

262 (PCR) and ligand-binding studies (Andersson et al. 2004; Carroll et al. 1997; Guillaudeau et al.

263 2012; Kurihara et al. 1989; Laurendeau et al. 2009; Torp et al. 1992; Weisman et al. 1987). As

264 such, immunohistochemistry appears as a reliable and practical method to determine EGFR

265 expression in meningioma tissue. For instance, this may be useful in diagnostics to distinguish

266 between normal and neoplastic meninges as well as to detect meningioma infiltration in soft

267 tissue. The upregulation of EGFR in neoplastic meningeal tissue supports a role of this receptor

268 as a facilitator in the tumorigenesis of these tumors. Whether this is linked to tumor initiation or

269 progression is however unclear. The increased levels of EGFR may be a result of enhanced

270 transcription, translation or decreased receptor turnover, but is not likely due to gene

271 amplification, as this is not described in meningiomas (Guillaudeau et al. 2012; Torp et al. 1992).

272

273 Few studies have focused on the different expression patterns of the internal and external

274 domains of EGFR in human meningiomas (Guillaudeau et al. 2012). In the present study, nearly

275 all tumors expressed both domains ( $99.5 \%$ for the ECD, $100 \%$ for ICD), even though the internal

276 domain had an overall higher intensity. High levels of ICD positivity have also been observed in

277 high-grade astrocytomas and non-small cell lung cancer (Gulati et al. 2010; Mascaux et al. 2011;

278 Torp et al. 2007), although negative immunoreactivity has also been reported (Wickremesekera 
279 et al. 2010). Concerning the ECD, most studies have shown high expression (Andersson et al.

280 2004; Baxter et al. 2014; Camby et al. 1997; Diedrich et al. 1995; Guillaudeau et al. 2012),

281 whereas some have recorded lower positivity (Jones et al. 1990). The observed stronger

282 expression of the ICD compared with the ECD may be a result of a fragile ECD damaged during

283 tissue processing or due to various shedding mechanisms (sEGFR) (Perez-Torres et al. 2008). In

284 high-grade astrocytomas such a discrepancy may be due to EGFR gene mutation and truncated

285 receptors, which have not been reported in meningiomas (Aldape et al. 2004; Fan et al. 2013;

286 Guillaudeau et al. 2012; Torp et al. 1992). Contradictory to our findings, Guillaudeau et al. found

287 higher expression of the extracellular domain compared with the intracellular domain

288 (Guillaudeau et al. 2012). The mechanisms of these discrepancies remain uncertain, but

289 expression of different EGFR isoforms and various antibodies may be part of the issue

290 (Guillaudeau et al. 2012).

291

292 In agreement with others, widespread EGF and TGF $\alpha$ immunoreactivity was observed in all

293 meningiomas (Carroll et al. 1997; Halper et al. 1999; Hsu et al. 1998; Torp et al. 1993). Both

294 cytoplasmic and membranous localizations were found, with the latter showing lower intensity.

295 However, some did not find any membranous positivity for TGF $\alpha$ (Halper et al. 1999; Hsu et al.

296 1998). Strong cytoplasmic reactivity may either be due to antibodies binding ligands produced in

297 the tumor cells or internalized ligand-receptor complexes (Tomas et al. 2014). Expression of

298 these EGFR ligands in meningioma tissue has also been demonstrated by other techniques such

299 as Northern and protein blots, PCR, in situ hybridization, and radioimmunoassays (Carroll et al.

300 1997; Halper et al. 1999; Torp et al. 1993), supporting the applicability of immunohistochemistry

301 to investigate the presence of these ligands as well. Furthermore, these findings support the 
302 existence of autocrine/paracrine growth loops in human meningiomas.

303

304 EGFR expression alone does not reveal the activation status, so clarifying whether the receptor is

305 activated or not is relevant. There are sparse data on this issue in meningioma tissue (Carroll et

306 al. 1997; Hilton et al. 2016), and according to our findings the activated receptor is expressed at

307 high levels in most tumors. In their study, Hilton et al. found significantly higher expression of

308 phosphorylated EGFR in tumor tissues compared with non-neoplastic tissues, and high

309 expression of downstream signaling molecules (Hilton et al. 2016). The literature is conflicting

310 concerning EGFR and malignancy, as some have found that high expression is positively related

311 to tumor grade (Caltabiano et al. 2013; Diedrich et al. 1995; Halper et al. 1999) whereas others

312 have found the opposite or no differences (Baxter et al. 2014; Guillaudeau et al. 2012; Jones et

313 al. 1990; Kuratsu et al. 1994; Narla et al. 2014; Wernicke et al. 2010). However, these previous

314 studies have not investigated the activated receptor. Thus, our results suggest that the expression

315 level of the activated receptor can be useful in meningioma grading.

317 Both membranous and cytoplasmic EGFR immunoreactivity were observed in the meningioma

318 tissue, however, membranous reactivity dominated in most cases for all the antibodies.

319 Distinguishing between these patterns of immunostaining was often problematic, mostly due to

320 high cellularity and fibrous growth. For this reason it seems inappropriate to make such a

321 distinction in human meningiomas, although it may be of clinical relevance in other human

322 malignancies such as renal cell carcinoma (Pu et al. 2009). A study on colorectal cancer,

323 however, demonstrated that cellular EGFR localization was unrelated to clinicopathological

324 parameters or patient outcome (McKay et al. 2002). 
326 Despite the uniform histological appearance of meningiomas, we observed both heterogeneous

327 immunoreactivity in the form of hotspots and homogeneous EGFR immunoreactivity, pointing to

328 meningiomas as heterogeneous in this regard. EGFR expression also varied with regard to

329 meningioma subtypes, suggesting that EGFR may play different roles in tumorigenesis of these

330 variants. Concerning histology, the association between high expression of the internal and

331 external domains and absence of psammoma bodies is interesting as the latter favors poorer

332 survival (Backer-Grondahl et al. 2014). Further, imaging studies suggest that calcified

333 meningiomas have a slower growth rate compared with calcified tumors (Nakamura et al. 2003;

334 Nakasu et al. 2005). Accordingly, if there exists a connection between microscopic- (psammoma

335 bodies) and macroscopic calcification, EGFR immunostaining may act as a marker for fast 336 growing tumors.

338 Concerning survival, only high expression of ECD was significantly associated with decreased

339 TTR, also when benign meningiomas were evaluated separately. Thus, high expression of ECD

340 may be an indicator of recurrence-prone benign meningiomas. This is in contrast to other studies,

341 which report better survival with high levels of ECD and similarily, poorer survival with low

342 expression of ECD (Guillaudeau et al. 2012; Smith et al. 2007). Others report no association

343 between EGFR expression and survival (Caltabiano et al. 2013). Contrary to our findings, Maiuri

344 et al. found higher EGFR positivity in non-recurrent benign meningiomas (Maiuri et al. 2007).

345 Further, we observed no association between antibody expression and OS. These discrepancies

346 may be due to different antibodies, tumor size, observation time and endpoints. The expression

347 of the ECD, however, was not significant in the multivariable analysis. ECD SI is therefore not 
348 an independent predictor of survival for meningioma patients. Thus, the prognostic value of

349 EGFR in human meningiomas appears uncertain and needs to be further clarified.

350

351 The key strengths of this study are a population-based study design with long observation time

352 and a large number of patients. Limitations are its retrospective profile and the subjective nature

353 of immunohistochemistry. To compensate for interobserver variability, all cases were evaluated

354 by two observers independently. In addition, the weighted kappa-statistics showed moderate or

355 substantial agreement (Landis \& Koch 1977), suggesting reproducible results. Another

356 uncertainty is the antigenicity of the archived tumor samples (Economou et al. 2014), which may

357 vary between tumors since the inclusion period was over 10 years. The use of TMAs has

358 potential advantages and disadvantages, and our evaluation of the immunostainings might have

359 been interfered by heterogeneous expression pattern. To compensate for this we tried to include

360 TMA cores representing the varying histological patterns. All in all, TMAs have benefits in

361 many aspects such as reproducibility and uniform assay conditions (Camp et al. 2008; Voduc et

362 al. 2008).

363

364 Conclusions

365

366 EGFR and its ligands are frequently overexpressed in human meningiomas compared with

367 normal meninges, and the receptor is generally in an activated state. These findings support the

368 role of this growth factor system in the tumorigenesis of these tumors. Accordingly, EGFR is a

369 potential candidate for targeted therapy. Regarding clinical value, only overexpression of the

370 external domain of EGFR was associated with prognosis in univariable analyses. It was not, 
371 however, significant in the multivariable analysis, and as such EGFR status appears to have

372 minor significance as a prognosticator.

373

374 Abbreviations

375 EGFR: epidermal growth factor receptor; ECD: extracellular domain; ICD: intracellular domain;

376 HER: human epidermal growth factor receptor; EGF: epidermal growth factor; TGF $\alpha$ :

377 transforming growth factor alpha; TMA: tissue microarray; EMA: epithelial membrane antigen;

378 SI: staining index; TTR: time to recurrence; OS: overall survival; HR: hazard ratio; PCR:

379 polymerase chain reaction.

380

381 Acknowledgements

382 The authors would like to thank prof. Anna Mary Bofin $\mathrm{MD}, \mathrm{PhD}$ for her assistance and advice

383 in the study, Øyvind Salvesen PhD for statistical assistance, and prof. Ivar Skjåk Nordrum MD,

$384 \mathrm{PhD}$ and Rosilin Varughese $\mathrm{MD}, \mathrm{PhD}$ for constructive criticism on the manuscript. A special

385 thanks to Kathrin Torseth PhD, Camilla Bjørk Setsaas, and Ingunn Nervik at the Cellular and

386 Molecular Imaging Core Facility (CMIC), Department of Laboratory Medicine, Children's and

387 Women's Health at the Norwegian University of Science and Technology (NTNU) where the

388 procedures for this article were performed.

389

390

391

392

393

394

395

396

397

398

399

\section{References}

Aldape KD, Ballman K, Furth A, Buckner JC, Giannini C, Burger PC, Scheithauer BW, Jenkins RB, and James CD. 2004. Immunohistochemical detection of EGFRvIII in high malignancy grade astrocytomas and evaluation of prognostic significance. J Neuropathol Exp Neurol 63:700-707.

Andersson U, Guo D, Malmer B, Bergenheim AT, Brannstrom T, Hedman H, and Henriksson R. 2004. Epidermal growth factor receptor family (EGFR, ErbB2-4) in gliomas and meningiomas. Acta Neuropathol 108:135-142. 10.1007/s00401-004-0875-6

Backer-Grondahl T, Moen BH, Sundstrom SH, and Torp SH. 2014. Histopathology and 
400

401

402

403

404

405

406

407

408

409

410

411

412

413

414

415

416

417

418

419

420

421

422

423

424

425

426

427

428

429

430

431

432

433

434

435

436

437

438

439

440

441

442

443

444

445 prognosis in human meningiomas. APMIS 122:856-866. 10.1111/apm. 12248

Backer-Grondahl T, Moen BH, and Torp SH. 2012. The histopathological spectrum of human meningiomas. Int J Clin Exp Pathol 5:231-242.

Baxter DS, Orrego A, Rosenfeld JV, and Mathiesen T. 2014. An audit of immunohistochemical marker patterns in meningioma. J Clin Neurosci 21:421-426. 10.1016/j.jocn.2013.06.008

Caltabiano R, Barbagallo GM, Castaing M, Cassenti A, Senetta R, Cassoni P, Albanese V, and Lanzafame S. 2013. Prognostic value of EGFR expression in de novo and progressed atypical and anaplastic meningiomas: an immunohistochemical and fluorescence in situ hybridization pilot study. J Neurosurg Sci 57:139-151.

Camby I, Nagy N, Rombaut K, Gras T, Duponchelle C, Pasteels JL, Brotchi J, Kiss R, and Salmon I. 1997. Influence of epidermal growth factor and gastrin on the cell proliferation of human meningiomas versus astrocytic tumors maintained as ex vivo tissue cultures. Neuropeptides 31:217-225.

Camp RL, Neumeister V, and Rimm DL. 2008. A decade of tissue microarrays: progress in the discovery and validation of cancer biomarkers. J Clin Oncol 26:5630-5637. 10.1200/JCO.2008.17.3567

Carroll RS, Black PM, Zhang J, Kirsch M, Percec I, Lau N, and Guha A. 1997. Expression and activation of epidermal growth factor receptors in meningiomas. J Neurosurg 87:315323. 10.3171/jns.1997.87.2.0315

Di Carlo A, Mariano A, Macchia PE, Moroni MC, Beguinot L, and Macchia V. 1992. Epidermal growth factor receptor in human brain tumors. J Endocrinol Invest 15:31-37. 10.1007/BF03348650

Diedrich U, Lucius J, Baron E, Behnke J, Pabst B, and Zoll B. 1995. Distribution of epidermal growth factor receptor gene amplification in brain tumours and correlation to prognosis. $J$ Neurol 242:683-688.

Economou M, Schoni L, Hammer C, Galvan JA, Mueller DE, and Zlobec I. 2014. Proper paraffin slide storage is crucial for translational research projects involving immunohistochemistry stains. Clin Transl Med 3:4. 10.1186/2001-1326-3-4

Fan QW, Cheng CK, Gustafson WC, Charron E, Zipper P, Wong RA, Chen J, Lau J, KnobbeThomsen C, Weller M, Jura N, Reifenberger G, Shokat KM, and Weiss WA. 2013. EGFR phosphorylates tumor-derived EGFRvIII driving STAT3/5 and progression in glioblastoma. Cancer Cell 24:438-449. 10.1016/j.ccr.2013.09.004

Fernebro E, Dictor M, Bendahl PO, Ferno M, and Nilbert M. 2002. Evaluation of the tissue microarray technique for immunohistochemical analysis in rectal cancer. Arch Pathol Lab Med 126:702-705. 10.1043/0003-9985(2002)126<0702:EOTTMT>2.0.CO;2

Guillaudeau A, Durand K, Bessette B, Chaunavel A, Pommepuy I, Projetti F, Robert S, Caire F, Rabinovitch-Chable H, and Labrousse F. 2012. EGFR soluble isoforms and their transcripts are expressed in meningiomas. PLoS One 7:e37204. 10.1371/journal.pone.0037204

Gulati S, Ytterhus B, Granli US, Gulati M, Lydersen S, and Torp SH. 2010. Overexpression of cerbB2 is a negative prognostic factor in anaplastic astrocytomas. Diagn Pathol 5:18. 10.1186/1746-1596-5-18

Halper J, Jung C, Perry A, Suliman H, Hill MP, and Scheithauer B. 1999. Expression of TGFalpha in meningiomas. J Neurooncol 45:127-134.

Hilton DA, Shivane A, Kirk L, Bassiri K, Enki DG, and Hanemann CO. 2016. Activation of multiple growth factor signalling pathways is frequent in meningiomas. Neuropathology 
446

447

448

449

450

451

452

453

454

455

456

457

458

459

460

461

462

463

464

465

466

467

468

469

470

471

472

473

474

475

476

477

478

479

480

481

482

483

484

485

486

487

488

489

490

491

36:250-261. 10.1111/neup.12266

Hoos A, Urist MJ, Stojadinovic A, Mastorides S, Dudas ME, Leung DH, Kuo D, Brennan MF, Lewis JJ, and Cordon-Cardo C. 2001. Validation of tissue microarrays for immunohistochemical profiling of cancer specimens using the example of human fibroblastic tumors. Am J Pathol 158:1245-1251. 10.1016/S0002-9440(10)64075-8

Horsfall DJ, Goldsmith KG, Ricciardelli C, Skinner JM, Tilley WD, and Marshall VR. 1989. Steroid hormone and epidermal growth factor receptors in meningiomas. Aust N Z J Surg 59:881-888.

Hsu DW, Efird JT, and Hedley-Whyte ET. 1998. MIB-1 (Ki-67) index and transforming growth factor-alpha (TGF alpha) immunoreactivity are significant prognostic predictors for meningiomas. Neuropathol Appl Neurobiol 24:441-452.

Huisman TW, Tanghe HL, Koper JW, Reubi JC, Foekens JA, Avezaat CJ, Braakman R, and Lamberts SW. 1991. Progesterone, oestradiol, somatostatin and epidermal growth factor receptors on human meningiomas and their CT characteristics. Eur J Cancer 27:14531457.

Johnson MD, Horiba M, Winnier AR, and Arteaga CL. 1994. The epidermal growth factor receptor is associated with phospholipase C-gamma 1 in meningiomas. Hum Pathol 25:146-153.

Jones NR, Rossi ML, Gregoriou M, and Hughes JT. 1990. Epidermal growth factor receptor expression in 72 meningiomas. Cancer 66:152-155.

Kirschner MW. 2005. The meaning of systems biology. Cell 121:503-504. 10.1016/j.cell.2005.05.005

Kuratsu JI, Seto H, Kochi M, and Ushio Y. 1994. Expression of PDGF, PDGF-receptor, EGFreceptor and sex hormone receptors on meningioma. Acta Neurochir (Wien) 131:289293.

Kurihara M, Tokunaga Y, Tsutsumi K, Kawaguchi T, Shigematsu K, Niwa M, and Mori K. 1989. Characterization of insulin-like growth factor I and epidermal growth factor receptors in meningioma. J Neurosurg 71:538-544. 10.3171/jns. 1989.71.4.0538

Landis JR, and Koch GG. 1977. The measurement of observer agreement for categorical data. Biometrics 33:159-174.

Laurendeau I, Ferrer M, Garrido D, D'Haene N, Ciavarelli P, Basso A, Vidaud M, Bieche I, Salmon I, and Szijan I. 2009. Gene expression profiling of ErbB receptors and ligands in human meningiomas. Cancer Invest 27:691-698. 10.1080/07357900802709175

Libermann TA, Razon N, Bartal AD, Yarden Y, Schlessinger J, and Soreq H. 1984. Expression of epidermal growth factor receptors in human brain tumors. Cancer Res 44:753-760.

Louis DN, Ohgaki H, Wiestler OD, and Cavenee WK. IARC: Lyon 2007. WHO Classification of Tumours of the Central Nervous System.:164, 172.

Lusis EA, Chicoine MR, and Perry A. 2005. High throughput screening of meningioma biomarkers using a tissue microarray. J Neurooncol 73:219-223. 10.1007/s11060-0045233-y

Maiuri F, De Caro MB, Esposito F, Cappabianca P, Strazzullo V, Pettinato G, and de Divitiis E. 2007. Recurrences of meningiomas: predictive value of pathological features and hormonal and growth factors. J Neurooncol 82:63-68. 10.1007/s11060-005-9078-9

Mascaux C, Wynes MW, Kato Y, Tran C, Asuncion BR, Zhao JM, Gustavson M, Ranger-Moore J, Gaire F, Matsubayashi J, Nagao T, Yoshida K, Ohira T, Ikeda N, and Hirsch FR. 2011. EGFR protein expression in non-small cell lung cancer predicts response to an EGFR 
492

493

494

495

496

497

498

499

500

501

502

503

504

505

506

507

508

509

510

511

512

513

514

515

516

517

518

519

520

521

522

523

524

525

526

527

528

529

530

531

532

533

534

535

536

537

tyrosine kinase inhibitor--a novel antibody for immunohistochemistry or AQUA technology. Clin Cancer Res 17:7796-7807. 10.1158/1078-0432.CCR-11-0209

McKay JA, Murray LJ, Curran S, Ross VG, Clark C, Murray GI, Cassidy J, and McLeod HL. 2002. Evaluation of the epidermal growth factor receptor (EGFR) in colorectal tumours and lymph node metastases. Eur J Cancer 38:2258-2264.

Nakamura M, Roser F, Michel J, Jacobs C, and Samii M. 2003. The natural history of incidental meningiomas. Neurosurgery 53:62-70; discussion 70-61.

Nakasu S, Fukami T, Nakajima M, Watanabe K, Ichikawa M, and Matsuda M. 2005. Growth pattern changes of meningiomas: long-term analysis. Neurosurgery 56:946-955; discussion 946-955.

Narla S, Uppin MS, Saradhi MV, Sahu BP, Purohit AK, and Sundaram C. 2014. Assessment of expression of epidermal growth factor receptor and p53 in meningiomas. Neurol India 62:37-41. 10.4103/0028-3886.128276

Perez-Torres M, Valle BL, Maihle NJ, Negron-Vega L, Nieves-Alicea R, and Cora EM. 2008. Shedding of epidermal growth factor receptor is a regulated process that occurs with overexpression in malignant cells. Exp Cell Res 314:2907-2918. 10.1016/j.yexcr.2008.07.013

Pu YS, Huang CY, Kuo YZ, Kang WY, Liu GY, Huang AM, Yu HJ, Lai MK, Huang SP, Wu WJ, Chiou SJ, and Hour TC. 2009. Characterization of membranous and cytoplasmic EGFR expression in human normal renal cortex and renal cell carcinoma. J Biomed Sci 16:82. 10.1186/1423-0127-16-82

Punt CJ, Buyse M, Kohne CH, Hohenberger P, Labianca R, Schmoll HJ, Pahlman L, Sobrero A, and Douillard JY. 2007. Endpoints in adjuvant treatment trials: a systematic review of the literature in colon cancer and proposed definitions for future trials. J Natl Cancer Inst 99:998-1003. 10.1093/jnci/djm024

Reubi JC, Horisberger U, Lang W, Koper JW, Braakman R, and Lamberts SW. 1989. Coincidence of EGF receptors and somatostatin receptors in meningiomas but inverse, differentiation-dependent relationship in glial tumors. Am J Pathol 134:337-344.

Rokita M, Stec R, Bodnar L, Charkiewicz R, Korniluk J, Smoter M, Cichowicz M, Chyczewski L, Niklinski J, Kozlowski W, and Szczylik C. 2013. Overexpression of epidermal growth factor receptor as a prognostic factor in colorectal cancer on the basis of the Allred scoring system. Onco Targets Ther 6:967-976. 10.2147/OTT.S42446

Rubin MA, Dunn R, Strawderman M, and Pienta KJ. 2002. Tissue microarray sampling strategy for prostate cancer biomarker analysis. Am J Surg Pathol 26:312-319.

Salomon DS, Brandt R, Ciardiello F, and Normanno N. 1995. Epidermal growth factor-related peptides and their receptors in human malignancies. Crit Rev Oncol Hematol 19:183-232.

Smith JS, Lal A, Harmon-Smith M, Bollen AW, and McDermott MW. 2007. Association between absence of epidermal growth factor receptor immunoreactivity and poor prognosis in patients with atypical meningioma. J Neurosurg 106:1034-1040. 10.3171/jns.2007.106.6.1034

Tomas A, Futter CE, and Eden ER. 2014. EGF receptor trafficking: consequences for signaling and cancer. Trends Cell Biol 24:26-34. 10.1016/j.tcb.2013.11.002

Torp S, Unsgaard G, and Dalen A. 1993. Epidermal growth-factor and transforming growth factor-alpha in human meningiomas. Int J Oncol 2:763-765.

Torp SH, Gulati S, Johannessen E, and Dalen A. 2007. Coexpression of c-erbB 1-4 receptor proteins in human glioblastomas. An immunohistochemical study. J Exp Clin Cancer Res 
538

539

540

541

542

543

544

545

546

547

548

549

550

551

552

553

554

555

556

557

558

559

560

561

562

563

564

565

566

567

568

569

570

571

572

573

574

575

576

577

578

579

580

581

582

26:353-359.

Torp SH, Helseth E, Dalen A, and Unsgaard G. 1992. Expression of epidermal growth factor receptor in human meningiomas and meningeal tissue. APMIS 100:797-802.

Torp SH, Helseth E, Ryan L, Stolan S, Dalen A, and Unsgaard G. 1991. Amplification of the epidermal growth factor receptor gene in human gliomas. Anticancer Res 11:2095-2098.

Uhlen M, Oksvold P, Fagerberg L, Lundberg E, Jonasson K, Forsberg M, Zwahlen M, Kampf C, Wester K, Hober S, Wernerus H, Bjorling L, and Ponten F. 2010. Towards a knowledgebased Human Protein Atlas. Nat Biotechnol 28:1248-1250. 10.1038/nbt1210-1248

Voduc D, Kenney C, and Nielsen TO. 2008. Tissue microarrays in clinical oncology. Semin Radiat Oncol 18:89-97. 10.1016/j.semradonc.2007.10.006

Weisman AS, Raguet SS, and Kelly PA. 1987. Characterization of the epidermal growth factor receptor in human meningioma. Cancer Res 47:2172-2176.

Wernicke AG, Dicker AP, Whiton M, Ivanidze J, Hyslop T, Hammond EH, Perry A, Andrews DW, and Kenyon L. 2010. Assessment of Epidermal Growth Factor Receptor (EGFR) expression in human meningioma. Radiat Oncol 5:46. 10.1186/1748-717X-5-46

Wickremesekera A, Hovens CM, and Kaye AH. 2010. Expression of ErbB-1 and ErbB-2 in meningioma. J Clin Neurosci 17:1155-1158. 10.1016/j.jocn.2010.02.006

Willis J, Smith C, Ironside JW, Erridge S, Whittle IR, and Everington D. 2005. The accuracy of meningioma grading: a 10-year retrospective audit. Neuropathol Appl Neurobiol 31:141149. 10.1111/j.1365-2990.2004.00621.x

www.ssb.no. 2013. Statistics Norway, Statistical Yearbook of Norway 2013, Table 50: "Population, land area and population density, by county".

Yarden Y, and Sliwkowski MX. 2001. Untangling the ErbB signalling network. Nat Rev Mol Cell Biol 2:127-137. 10.1038/35052073 
Table 1: Immunohistochemical findings

585

\begin{tabular}{|l|l|c|c|c|c|}
\hline Antibody & Measure & $\begin{array}{c}\text { All grades } \\
(\mathbf{n = 1 8 6})\end{array}$ & $\begin{array}{c}\text { Grade I } \\
(\mathbf{n = 1 3 0})\end{array}$ & $\begin{array}{c}\text { Grade II } \\
(\mathbf{n = 5 5})\end{array}$ & $\begin{array}{c}\text { Grade III } \\
(\mathbf{n = 1})\end{array}$ \\
\hline EGFR25 (ICD) & Percent positive & 100 & 100 & 100 & 100 \\
\hline & Median SI (min-max) & $9(2-9)$ & $9(2-9)$ & $9(2-9)$ & $9(9)$ \\
\hline & Mean SI & 7.95 & 7.94 & 7.96 & 9.00 \\
\hline $\begin{array}{l}\text { EGFR113 } \\
\text { (ECD) }\end{array}$ & Percent positive & 99.5 & 99.2 & 100 & 100 \\
\hline & & & & \\
\hline & Median SI (min-max) & $4(0-9)$ & $4(0-9)$ & $6(2-9)$ & $9(9)$ \\
\hline $\begin{array}{l}\text { Phosphorylated } \\
\text { EGFR }\end{array}$ & Mean SI & 4.89 & 4.87 & 4.87 & 9.00 \\
\hline & Percent positive & 99.5 & 99.2 & 100 & 100 \\
\hline & Median SI (min-max) & $9(0-9)$ & $9(0-9)$ & $9(6-9)$ & $9(9)$ \\
\hline EGF & Mean SI & 8.40 & 8.24 & 8.78 & 9.00 \\
\hline & Percent positive & 100 & 100 & 100 & 100 \\
\hline & Median SI (min-max) & $9(1-9)$ & $9(2-9)$ & $6(1-9)$ & $3(3)$ \\
\hline TGFa & Mean SI & 7.42 & 7.62 & 7.05 & 3.00 \\
\hline & Percent positive & 100 & 100 & 100 & 100 \\
\hline & Median SI (min-max) & $9(6-9)$ & $9(6-9)$ & $9(6-9)$ & $9(9)$ \\
\hline & Mean SI & 8.81 & 8.75 & 8.95 & 9.00 \\
\hline
\end{tabular}

586 Percent positive: the percent of cases with a SI of 1 or higher

587 SI: staining index

588 ICD: intracellular domain

589 ECD: extracellular domain

590

591

592

593

594

595

596

597

598

599

600

601

602

603

604

605

606

607

608 
610 Table 2: Comparison of antibody SI and histological features (p-values, 2-tailed exact values 611 from Mann-Whitney U tests).

612

\begin{tabular}{|l|c|c|c|c|c|}
\hline & $\begin{array}{c}\text { EGFR25 } \\
\text { (ICD) }\end{array}$ & $\begin{array}{c}\text { EGFR113 } \\
\text { (ECD) }\end{array}$ & Ph-EGFR & EGF & TGFa \\
\hline $\begin{array}{l}\text { Mitosis 4+ } \\
\text { (n=41) }\end{array}$ & 0.430 & 0.317 & 0.057 & 0.545 & 0.307 \\
\hline $\begin{array}{l}\text { Brain infiltration present } \\
\text { (n=13) }\end{array}$ & 0.248 & 0.221 & 0.574 & 0.254 & 1.000 \\
\hline $\begin{array}{l}\text { Sheeting present } \\
\text { (n=14) }\end{array}$ & 0.509 & $\mathbf{0 . 0 3 5}$ & 0.133 & 0.467 & 0.604 \\
\hline $\begin{array}{l}\text { Macronucleoli present } \\
\text { (n=11) }\end{array}$ & 0.440 & 0.684 & 0.216 & 0.478 & 0.622 \\
\hline $\begin{array}{l}\text { Hypercellularity absent } \\
\text { (n=140) }\end{array}$ & 0.200 & 0.579 & 0.445 & $<\mathbf{0 . 0 0 1}$ & 0.733 \\
\hline $\begin{array}{l}\text { Small cell change present } \\
\text { (n=18) }\end{array}$ & 0.228 & 0.259 & 0.206 & 0.509 & 0.380 \\
\hline $\begin{array}{l}\text { Necrosis present } \\
\text { (n=40) }\end{array}$ & 0.416 & 0.877 & 1.000 & 0.210 & 0.073 \\
\hline $\begin{array}{l}\text { Psammoma bodies absent } \\
\text { (n=61) }\end{array}$ & $\mathbf{0 . 0 0 5}$ & $<\mathbf{0 . 0 0 1}$ & 0.259 & 0.168 & 0.108 \\
\hline $\begin{array}{l}\text { Grade II vs grade I } \\
\text { (total: n=185) }\end{array}$ & 0.983 & 0.787 & $\mathbf{0 . 0 1 8} \dagger$ & $\mathbf{0 . 0 4 0 *}$ & 0.113 \\
\hline Vals in bol & & & & & \\
\hline
\end{tabular}

613 Values in bold: statistically significant. Ph-EGFR: phosphorylated EGFR. Brain infiltration:

$614 \mathrm{n}=65$ where brain tissue was observed. $\uparrow$ SI significantly higher in Grade II than in Grade I. * SI

615 significantly higher in Grade I than in Grade II. p-values between 1\% and 5\% should be

616 interpreted with caution due to multiple hypotheses. (The present/absent annotations in the first

617 column indicate the characteristic associated with high SI values for bold values only).

618

619

620

621 
623 Table 3: Survival analyses (Cox regression, univariable).

624

\begin{tabular}{|l|l|l|l|}
\hline Antibody & Measure & $\begin{array}{l}\text { Time to } \\
\text { recurrence } \\
\text { (n=61) }\end{array}$ & $\begin{array}{l}\text { Overall survival } \\
(\mathbf{n = 6 7 )}\end{array}$ \\
\hline ICD & HR & 1.054 & 1.065 \\
\hline & CI & 0.909 to 1.222 & 0.924 to 1.229 \\
\hline ECD & p-value & 0.484 & 0.383 \\
\hline & HR & $\mathbf{1 . 1 5 2}$ & 1.045 \\
\hline & CI & $\mathbf{1 . 0 3 6}$ to $\mathbf{1 . 2 8 0}$ & 0.941 to 1.160 \\
\hline Phosphorylated & p-value & $\mathbf{0 . 0 0 9}$ & 0.414 \\
\hline & HR & 1.058 & 1.120 \\
\hline & CI & 0.862 to 1.298 & 0.901 to 1.392 \\
\hline EGF & p-value & 0.591 & 0.308 \\
\hline & HR & 0.992 & 1.038 \\
\hline & CI & 0.884 to 1.113 & 0.927 to 1.163 \\
\hline TGF $\alpha$ & p-value & 0.889 & 0.516 \\
\hline & HR & 0.989 & 1.110 \\
\hline & CI & 0.705 to 1.387 & 0.754 to 1.634 \\
\hline & p-value & 0.949 & 0.596 \\
\hline
\end{tabular}

625

HR: hazard ratio $(\exp (\mathrm{B}))$

626

CI: confidence interval $(95 \%$ CI for $\exp (B))$

627

628

629

630

631

632

633

634

635

636

637

638

639

640

641

642

643

644

645

646

647

648

649 
651 Table 4: Multivariable analysis for EGFR ECD (TTR).

652

\begin{tabular}{|l|l|l|l|}
\hline Variable & HR & $\mathbf{9 5 \%}$ CI for HR & p-value \\
\hline EGFR ECD & 1.099 & 0.987 to 1.222 & 0.084 \\
\hline WHO grade & 1.460 & 0.868 to 2.455 & 0.154 \\
\hline Simpson grade & 2.606 & 1.558 to 4.359 & $<0.001$ \\
\hline WHO performance & 1.143 & 0.607 to 2.151 & 0.680 \\
\hline Age & 1.015 & 0.994 to 1.036 & 0.161 \\
\hline
\end{tabular}

653

654

655

656

657

658

659

660

661

662

663

664

665

666

667

668

669

670

671

672

673

674

675

676

677

678

679

680

681

682

683 
685 Figures:

686

687 Figure 1. Expression patterns for each antibody. Pictures were taken by MBA using a Nikon

688 eclipse 50i microscope with Nikon DS-Fi2 camera head and Nikon Digital Sight DS-L3 camera

689 controller. Exposure was set to +1.3 and original files were in TIF format. Lettering and

690 merging of pictures were done with Microsoft Paint. A EGF, 40x, SI 9. B TGF $\alpha$, 40x, SI 6. C

691 EGFR intracellular domain, 40x, SI 9. D extracellular domain, 40x, SI 9. E EGFR

692 phosphorylated, 40x, SI 9. F Non-neoplastic leptomeninges and adjacent tumor tissue

693 (EGFR25), 10x.

694

695

696

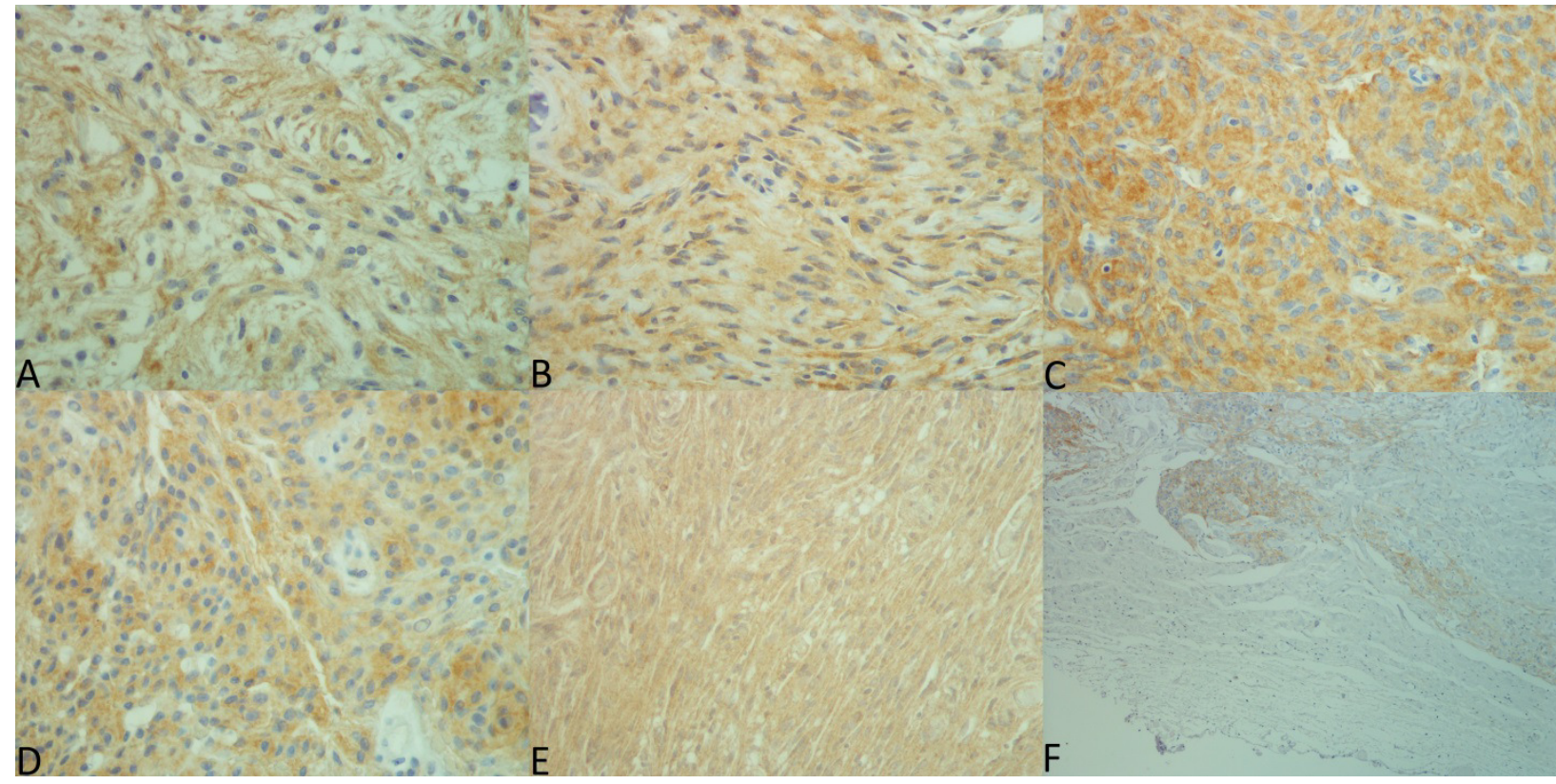

